\title{
Icariside II overcomes BRAF inhibitor resistance in melanoma by inducing ROS production and inhibiting MITF
}

\author{
XIAO LIU* ${ }^{*}$ ZHENG LI* ${ }^{*}$ MING LI, JINGXIU CHAI, SHAN HE, JINFENG WU and JINHUA XU \\ Department of Dermatology, Huashan Hospital, Fudan University, Shanghai 200040, P.R. China
}

Received September 24, 2019; Accepted March 18, 2020

DOI: 10.3892/or.2020.7582

\begin{abstract}
Metastatic melanoma is the most aggressive skin cancer. Although BRAF inhibitor treatment has achieved great success in melanoma, resistance develops within 12 months. Icariside II (IS), a natural compound extracted from Herba Epimedii, exerts anticancer properties. In the present study, we determined by MTT, flow cytometry and western blotting, respectively that IS potentiated the PLX4032-induced downregulation of cell viability and increase in apoptosis and autophagy in BRAF inhibitor-resistant melanoma. In addition, we also revealed by flow cytometry and western blotting, respectively, that IS combined with PLX4032 increased mitochondrial and intracellular reactive oxygen species (ROS) generation and subsequently promoted depolarization of mitochondria and release of apoptotic proteins. $\mathrm{N}$-acetyl cysteine (NAC) and glutathione (GSH), ROS scavengers, reversed the IS-induced enhancement of the response to PLX4032. Microphthalmia-associated transcription factor (MITF) and tyrosine-protein kinase Met (c-Met) are well-known factors that contribute to BRAF inhibitor resistance. Furthermore, c-Met is a direct transcriptional target of MITF in melanocytes and melanoma cells. It was also revealed that IS markedly inhibited MITF and c-Met expression partially by increasing ROS production in BRAF inhibitor-resistant melanoma cells.
\end{abstract}

Correspondence to: Dr Jinhua Xu or Dr Jinfeng Wu, Department of Dermatology, Huashan Hospital, Fudan University, 12 Middle Urumqi Road, Shanghai 200040, P.R. China

E-mail: xjhhsyy@163.com

E-mail: wujinfeng21@163.com

*Contributed equally

Abbreviations: IS, icariside II; ROS, reactive oxygen species; NAC, $\mathrm{N}$-acetyl cysteine; GSH, glutathione; DMEM, Dulbecco's modified Eagle's medium; FBS, fetal bovine serum; A375R cells, A375 BRAF inhibitor-resistant cells; ME, medium control; RTK, receptor tyrosine kinase; MITF, microphthalmia-associated transcription factor; c-Met, tyrosine-protein kinase Met

Key words: icariside II, melanoma, BRAF inhibitor resistance, reactive oxygen species, MITF

\section{Introduction}

Metastatic melanoma is the deadliest skin cancer and has an increasing incidence worldwide (1). It exhibits high metastatic potential and low response rates to conventional therapies, such as dacarbazine (2). It also has the highest mutational load in all cancers (3). Mutations in the BRAF gene which activate MAPK signaling and subsequently promote unrestricted melanoma growth, are the most common somatic events with an incidence of 40-60\% in melanoma patients (4). Targeted inhibitors towards BRAF, such as vemurafenib and dabrafenib, have been developed and approved by the U.S. Food and Drug Administration for the treatment of BRAF-mutant melanoma (5). Patients exhibited a high response rate of $\sim 50 \%$ to these BRAF inhibitors (6-8). In addition, these BRAF inhibitors improved the median progression-free survival to 75.1-8.8 months (6,8-11). However, resistance develops within 12 months as revealed by the median progression-free survival. Copy-number alterations, mutations, or expression changes that result in reactivation of the MAPK signaling pathway or activation of the PI3K/AKT signaling pathway are considered to contribute to BRAF inhibitor resistance in melanoma (5). Therefore, a combination of BRAF inhibitor and MEK inhibitor was used to treat BRAF-mutant melanoma. Such a combination was revealed to improve the objective response rates to $>60 \%$ and the median progression-free survival to 9.3-11.4 months $(11,8)$. However, almost all patients ultimately develop resistance to such combination therapies. Therefore, it is urgent to develop other new therapies to overcome BRAF inhibitor resistance in melanoma.

Icariside II (IS) also known as baohuoside I (Fig. 1A), a glycosyloxy flavone isolated from Herba Epimedii, has been identified as an anticancer agent against multiple cancers, such as non-small-cell lung cancer, multiple myeloma, osteosarcoma, glioblastoma, epidermoid carcinoma, breast cancer, esophageal carcinoma, prostate cancer and melanoma. It has been revealed to inhibit cell proliferation, promote apoptosis, and induce cell cycle arrest by targeting different signaling pathways including ROS mediated mitochondrial pathways, EGFR, AKT, MAPK, STAT3, COX-2/PEG2 and $\beta$-catenin, in these cancers (12-14). In addition, IS has the potential to improve the benefits of multiple therapies, such as chemotherapies and immunotherapies. Our previous study indicated that it could further improve paclitaxel-induced apoptosis by inhibiting TLR4 signaling in human melanoma cells (15). IS was also reported to overcome 
TRAIL resistance by regulating the ROS/STAT3/cFLIP signaling pathway (16). However, the role of IS in overcoming BRAF inhibitor resistance remains undefined.

In the present study, it was demonstrated that IS potentiated PLX4032-induced cytotoxicity, apoptosis, and autophagy in melanoma cells with either intrinsic or acquired resistance to BRAF inhibitors. Furthermore, it was revealed that IS significantly increased ROS production, and subsequently inhibited the expression of microphthalmia-associated transcription factor (MITF) and tyrosine-protein kinase Met (c-Met), well-known factors that contribute to BRAF inhibitor resistance. Therefore, IS serves as a potential agent that overcomes BRAF inhibitor resistance in melanoma.

\section{Materials and methods}

Cell culture and BRAF inhibitor-resistant melanoma cell line establishment. The human melanoma cell lines, A2058 and A375, were purchased from the American Type Culture Collection and cultured in Dulbecco's modified Eagle's medium (DMEM) supplemented with $10 \%$ fetal bovine serum (FBS) and 1\% penicillin/streptomycin (all from Invitrogen; Thermo Fisher Scientific, Inc.) at $37^{\circ} \mathrm{C}$ in a $5 \% \mathrm{CO}_{2}$ humidified incubator. Vemurafenib (PLX4032) (MedChemExpress, Inc.) resistant A375 melanoma cells (A375R) were generated by adding increasing concentrations of PLX4032 into A375 cells for more than half a year (17). The final concentration of PLX4032 used to maintain A375R was $2 \mu \mathrm{M}$. To verify whether A375R cells were resistant to PLX4032, both parental A375 and resistant A375R cells were treated with various concentrations $(0.1,0.5,1,5$ and $10 \mu \mathrm{M})$ of PLX4032 for $48 \mathrm{~h}$, and the cell viabilities were detected by MTT assay. Furthermore, both parental A375 and resistant A375R cells were treated with different concentrations $(0,2$ and $5 \mu \mathrm{M})$ of PLX4032 for $24 \mathrm{~h}$, and cell apoptosis was assessed by Annexin $\mathrm{V}$ and 7-AAD staining.

Cell viability assay. Cell viability was determined by MTT assay. Cells were seeded into 96 -well plates at a density of 5,000 cells/well and cultured in an incubator overnight at $37^{\circ} \mathrm{C}$ in $5 \% \mathrm{CO}_{2}$. Then various concentrations of PLX4032 (0, 7.5 and $10 \mu \mathrm{M})$ and/or IS (0, 20 and $25 \mu \mathrm{M}$ in A2058 cells; 0, 10 and $20 \mu \mathrm{M}$ in $\mathrm{A} 375 \mathrm{R}$ cells) were added into corresponding wells, and incubated for $48 \mathrm{~h}$ at $37^{\circ} \mathrm{C}$. For NAC/GSH treatment experiment, cells were pre-treated with $5 \mathrm{mM} \mathrm{NAC} / 1 \mathrm{mM}$ GSH for $1 \mathrm{~h}$, and then treated with PLX4032 (10 $\mu \mathrm{M})$ and IS $(20 \mu \mathrm{M})$ for another $18 \mathrm{~h}$. Next, $20 \mu \mathrm{l}$ MTT solution (Sigma-Aldrich; Merck KGaA) with a concentration of $5 \mathrm{mg} / \mathrm{ml}$ was added to every well and incubated at $37^{\circ} \mathrm{C}$ for 2-4 h. Subsequently, $100 \mu \mathrm{l}$ DMSO was added to each well to dissolve the formed formazan crystal. Finally, the optical density (OD) was detected at $492 \mathrm{~nm}$ using Infinite F200 Pro microplate reader (Tecan Group, Ltd.). The cell viabilities were calculated via the following formula: Cell viability $(\%)=($ mean OD treatment/mean OD control) x 100 .

Cell apoptosis assay. The cell apoptosis rates were determined by PE Annexin V Apoptosis Detection kit I (BD Biosciences) via flow cytometry according to the manufacturer's instructions. Briefly, cells were seeded in 6-well plates at a density of
$2 \times 10^{5}$ cells/well, and cultured in an incubator overnight at $37^{\circ} \mathrm{C}$ in $5 \% \mathrm{CO}_{2}$. Then PLX4032 (0 and $\left.10 \mu \mathrm{M}\right)$ and/or IS (0 and $\left.20 \mu \mathrm{M}\right)$ were added into corresponding wells, and incubated for 24 or $72 \mathrm{~h}$ at $37^{\circ} \mathrm{C}$. Next, the cells were harvested and washed three times with PBS (Gibco; Thermo Fisher Scientific, Inc.), and resuspended with $100 \mu \mathrm{l} 1 \mathrm{X}$ binding buffer, and then $5 \mu \mathrm{l} \mathrm{PE}$ Annexin V and $20 \mu \mathrm{l}$ 7-Amino-Actinomycin (7-AAD) were added into each tube and incubated at room temperature in the dark for $20 \mathrm{~min}$. Finally, the labeled cells were washed with $1 \mathrm{X}$ binding buffer, and the data were obtained by a flow cytometer (Attune NxT; Thermo Fisher Scientific, Inc.) and analyzed by FlowJo software v10.0 (Tree Star, Inc.).

Cellular ROS detection. A total of $20 \times 10^{4}$ cells were seeded into each well of a 6-well plate and incubated overnight. Then the cells were treated with vehicle control, IS, PLX4032, and IS+PLX4032 for $24 \mathrm{~h}$. The treated cells were loaded with DCFH-DA probes for $20 \mathrm{~min}$ at $37^{\circ} \mathrm{C}$, followed by a three-time wash with DMEM without FBS. Finally, the signals were detected by a flow cytometer and analyzed by FlowJo software v10.0.

Western-blotting. The treated cells were lysed in RIPA lysis buffer (Beyotime Institute of Biotechnology) containing $10 \%$ PMSF (Beyotime Institute of Biotechnology) at $4^{\circ} \mathrm{C}$ for 15 min with intermittent vortex, and then centrifuged at $4^{\circ} \mathrm{C}$ at $12,000 \mathrm{x} \mathrm{g}$ for $10 \mathrm{~min}$. The supernatants were immediately collected. The protein concentrations were measured by a BCA Protein Assay kit (Life Technology; Thermo Fisher Scientific, inc.), according to the manufacturer's instructions. In addition, 5X loading buffer (Beyotime Institute of Biotechnology) was added into the collected supernatants at a ratio of $1: 4$, and the mixture was heated at $100^{\circ} \mathrm{C}$ for $10 \mathrm{~min}$. Total amounts of $30 \mu \mathrm{g}$ cellular proteins were electrophoresed on $10 \%$ SDS-PAGE (Beyotime Institute of Biotechnology), and subsequently transferred onto polyvinylidene difluoride (PVDF) membranes (EMD Millipore), which was followed by blocking with $5 \%$ nonfat milk at room temperature for $1 \mathrm{~h}$. Then the membranes were incubated with the primary antibody at $4^{\circ} \mathrm{C}$ overnight, and followed by an incubating step with a secondary goat anti-rabbit antibody conjugated with horseradish peroxidase (HRP; product code ab6721; dilution 1:4,000; Abcam) for $1 \mathrm{~h}$ at room temperature. Finally, the bands were measured via ECL technology (Fujifilm LAS-3000; Fujifilm Corporation). The band intensities were quantified by ImageJ software (v1.37; National Institutes of Health). $\beta$-Actin was used as a loading control, and the relative band intensities were normalized to the medium control (ME) group. Primary antibodies against p53 (product code ab32389; dilution 1:1,000), phosphorylated (p)-p53 (product code ab1431; dilution 1:1,000), LC3B (product code ab192890; dilution 1:1,000), Beclin1 (product code ab207612; dilution 1:1,000), Bax (product code ab32503; dilution 1:1,000), Bcl-2 (product code ab32124; dilution 1:1,000), MITF (product code ab232415; dilution 1:1,000), c-Met (product code ab51067; dilution 1:1,000), and $\beta$-actin (product code ab8227; dilution 1:1,000) were supplied by Abcam.

Mitochondrial membrane potential detection. The treated cells were stained with the JC-1 fluorescent probe (Beyotime 
Institute of Biotechnology) following the manufacturer's instructions. The mitochondrial membrane potential was detected by a flow cytometer and analyzed by FlowJo software v10.0. We referred to the study of Chen et al to draw the cut-off line (18).

Mitochondrial ROS detection. A2058 or A375R cells were seeded into a 6 -well plate at a concentration of $2 \times 10^{5}$ cells/well, and treated with vehicle, PLX4032, IS, or PLX4032+IS for $24 \mathrm{~h}$. The treated cells were incubated with MitoROS ${ }^{\mathrm{TM}} 580$ (AAT Bioquest, Inc.) working solution for $30 \mathrm{~min}$ and washed 3 times with Hanks' solution with 20 mM HEPES buffer (AAT Bioquest, Inc.). The mean fluorescence intensity was detected by a cytometer and analyzed by FlowJo software v10.0.

Clonogenic assay. A total of 1,000 A2058 or A375R cells were seeded into each well of a 6-well plate and treated with vehicle, PLX4032, IS, or PLX40332+IS for 9 days. The medium was changed every 3 days. Finally, the treated cells were fixed with $4 \%$ paraformaldehyde for $1 \mathrm{~h}$ at $4^{\circ} \mathrm{C}$ and stained with $0.05 \%$ crystal violet solution for $15 \mathrm{~min}$ at room temperature.

Statistical analysis. All data were analyzed by GraphPad Prism 6 (GraphPad Software, Inc.) and presented as the mean \pm standard deviation of three independent experiments. For comparison of two independent groups, Student's t-test was used. For comparison of more than two independent groups, one-way ANOVA (one factor) or two-way ANOVA (two factors) and subsequent Tukey's post hoc analysis were applied. $\mathrm{P}<0.05$ was considered to indicate a statistically significant difference.

\section{Results}

IS potentiates PLX4032-induced cytotoxicity in BRAF inhibitor-resistant melanoma cells. To verify the effects of IS on BRAF inhibitor-resistant melanoma, the effects of PLX4032 and/or IS on the cell proliferation of two BRAF inhibitor-resistant melanoma cell lines, A2058 (intrinsic resistance) (19) and A375R (acquired resistance, Fig. S1A and B) were first evaluated. In the clonogenic assay, it was revealed that either PLX4032 or IS alone could inhibit the proliferation of both A2058 and A375R cells. Moreover, the combination of PLX4032 and IS revealed increased inhibition of cell proliferation compared to PLX4032 or IS alone (Fig. 1B and C). It was also demonstrated that in the MTT assay, various concentrations of PLX4032 or IS alone could decrease the cell viability of both A2058 and A375R cells, and combined IS and PLX4032 further reduced the cell viability of both A2058 and A375R cells $(\mathrm{P}<0.05$, Fig. $1 \mathrm{D}$ and $\mathrm{E})$. Moreover, IS and PLX4032 exhibited synergetic effects in inhibiting the proliferation of both A2058 and A375R cells (Fig. 1F and G).

IS enhances PLX4032-induced apoptosis and autophagy in BRAF inhibitor-resistant melanoma cells. The effects of PLX4032 and/or IS on the apoptosis of BRAF inhibitor-resistant cells were further examined by staining with Annexin $\mathrm{V}$ and 7-AAD. As revealed in Fig. 2A and B, cells treated with either PLX4032 or IS alone exhibited a higher apoptosis rate than ME-treated cells $(\mathrm{P}<0.05)$. In addition, the highest apoptosis rate was observed in cells treated with both PLX4032 and IS $(\mathrm{P}<0.05$, Fig. $2 \mathrm{~A}$ and $\mathrm{B})$. In addition, the highest expression of autophagy-related proteins, LC3B and Beclin1, was revealed in the PLX4032+IS group in both A2058 and A375R cells (Fig. 2C and D).

IS induces p53-dependent Bax accumulation and mitochondrial depolarization in BRAF inhibitor-resistant melanoma cells. Having revealed the effect of IS on cell proliferation, apoptosis and autophagy in BRAF inhibitor-resistant melanoma cells, the underlying mechanisms were next determined. As indicated in Fig. 3A and B, IS significantly decreased the percentages of JC-1 aggregates and increased the proportion of JC-1 monomers in A2058 cells, indicating that IS could induce mitochondrial depolarization $(\mathrm{P}<0.05)$. However, PLX4032 had little effect on mitochondrial membrane potential ( $\mathrm{P}>0.05$, Fig. $3 \mathrm{~A}$ and $\mathrm{B})$. In addition, it was revealed that the combination of PLX4032 and IS promoted the depolarization of mitochondria to a greater extent than IS or PLX4032 alone $(\mathrm{P}<0.05$, Fig. $3 \mathrm{~A}$ and $\mathrm{B})$.

The expression of two apoptotic regulators in the Bcl-2 family, Bax and Bcl-2, which are co-localized on the outer membrane of mitochondria and regulate the opening of mitochondrial voltage-dependent anion channels, thus moderating the mitochondrial membrane potential and release of cytochrome $c$, was then examined (20). As revealed in Fig. 3C, IS with or without PLX4032 significantly downregulated Bcl-2 expression and upregulated Bax levels in A2058 cells.

Given that p53 participates in apoptosis by directly interacting with and neutralizing Bcl-2 and Bcl-xL in mitochondria, and directly activating Bax in the cytosol (21), it was hypothesized that IS led to apoptosis by p53-dependent inhibition of Bcl-2, activation of Bax and subsequent mitochondrial membrane permeabilization. As anticipated, PLX4032 did not activate p53, while IS or IS+PLX4032 significantly upregulated the expression of p-p53 in A2058 cells (Fig. 3D).

IS promotes mitochondria-dependent ROS production, while ROS scavengers partially reverse IS-induced enhancement of the response to PLX4032 in BRAF inhibitor-resistant melanoma cells. Since higher ROS generation has been reported to sensitize resistant cells to BRAF inhibitors, the ROS levels in all four groups, i.e. ME, PLX4032, IS, PLX4032+IS, were then assessed. As anticipated, higher ROS levels were detected in the IS and PLX4032+IS groups than in the ME or PLX4032 alone group ( $\mathrm{P}<0.05$, Fig. 4A). Given the role of IS on the mitochondrial membrane, it was hypothesized that IS induced-ROS was generated from mitochondria. To verify this hypothesis, mitochondrial ROS levels were assessed in all groups in both A2058 and A375R cells. In accordance with total ROS generation, IS with or without PLX4032 significantly increased mitochondrial ROS levels ( $\mathrm{P}<0.05$; Fig. 4B).

To further confirm the role of ROS in the IS-improved response to PLX4032, NAC and GSH, ROS scavengers, were then used to eliminate ROS secretion, and it was detected whether combination of PLX4032 and IS inhibition of cell viability could be reversed. As indicated in Fig. $4 \mathrm{C}$ and D, the cell viability of NAC/GSH+PLX4032+IS-treated cells was significantly higher than that of PLX4032+IS-treated cells $(\mathrm{P}<0.05)$. 
A<smiles>COc1ccc(-c2oc3c(CC=C(C)C)c(O)cc(O)c3c(=O)c2OC2O[C@H](C)[C@@H](O)[C@H](O)[C@H]2O)cc1</smiles>

B

A2058

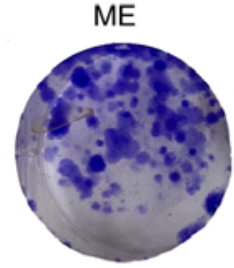

C

A375R

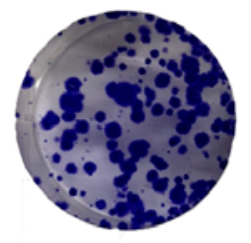

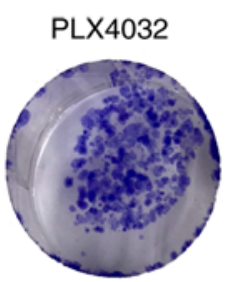

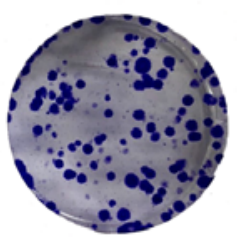

IS
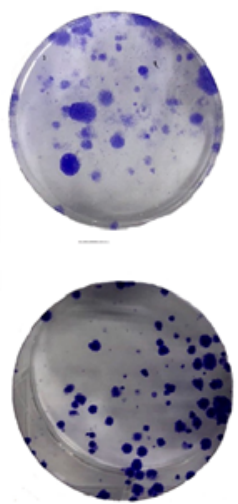

PLX4032+IS
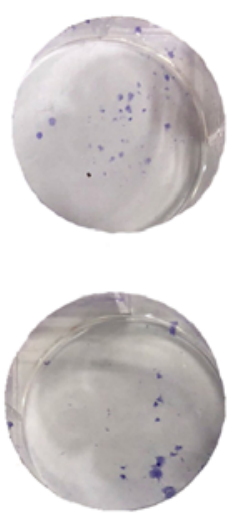

Icariside II (IS)

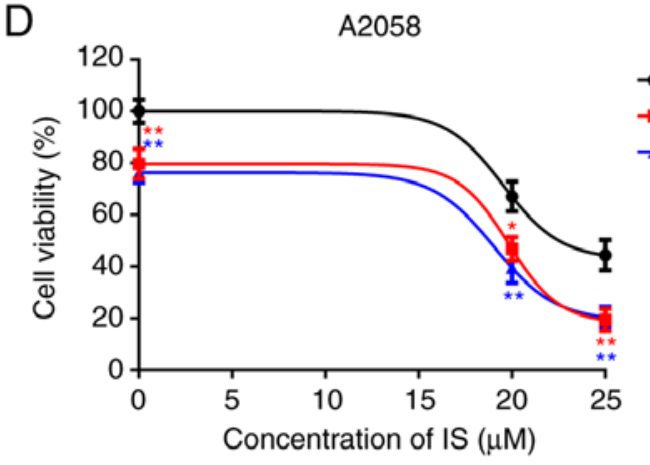

F

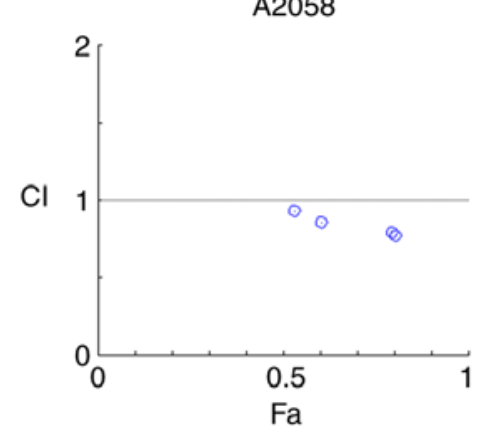

E

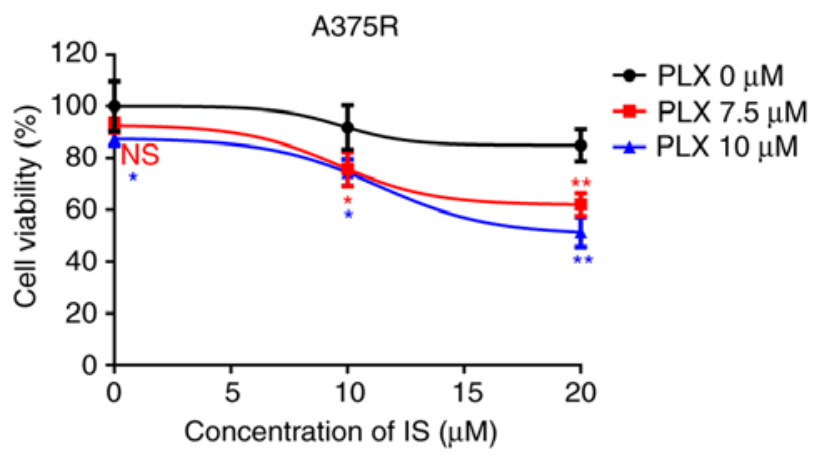

G

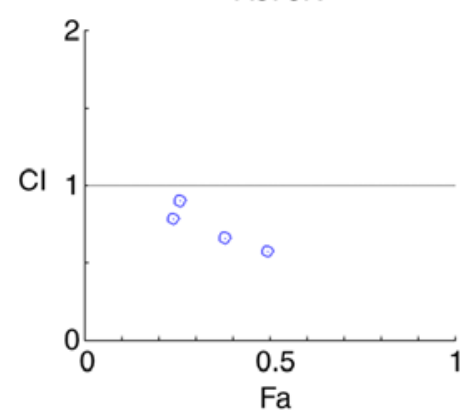

- PLX4032+IS

- PLX4032+IS

Figure 1. IS potentiates PLX4032-induced cytotoxicity in BRAF inhibitor-resistant melanoma cells. (A) Chemical structure of IS. Both (B) A2058 and (C) A375R cells were treated with ME, PLX4032 $(10 \mu \mathrm{M})$, IS (20 $\mu \mathrm{M})$, and PLX4032 $(10 \mu \mathrm{M})+\mathrm{IS}(20 \mu \mathrm{M})$, respectively. Nine days later, the long-term effects of IS and/or PLX4032 were assessed by clonogenic assay. Both (D) A2058 and (E) A375R cells were treated with various concentrations of PLX4032 (0, 7.5, $10 \mu \mathrm{M})$ and/or IS (0,20 and $25 \mu \mathrm{M}$ in A2058 cells; 0,10 and $20 \mu \mathrm{M}$ in A375R cells) for $48 \mathrm{~h}$ and cell viabilities were detected by MTT assay. The combination index of PLX4032 and IS in (F) A2058 and (G) A375R cells was calculated by CompuSyn. CI $<1$ indicates a synergistic effect; CI=1 indicates additivity; CI $>1$ indicates an antagonistic effect. Data were presented as the mean \pm standard error of the mean. A two-way ANOVA, with post hoc Tukey's test was applied for comparisons. ${ }^{*} \mathrm{P}<0.05$ and $^{* *} \mathrm{P}<0.01$. IS, icariside II; ME, medium control.

IS reduces the expression of MITF and $c$-Met by promoting ROS production. MITF and c-Met are well-known factors that contribute to BRAF inhibitor resistance (22-24). Furthermore, c-Met is a direct transcriptional target of MITF in melanocytes and melanoma cells (25). Therefore, the effects of IS on the expression of both MITF and c-Met, were then verified. As demonstrated in Fig. 5A-D, decreased mRNA and protein levels of MITF and c-Met were observed in the IS and IS+PLX4032 groups than in the ME group in both A2058 and A375R cells $(\mathrm{P}<0.05)$. However, PLX4032 alone could not markedly downregulate MITF expression (Fig. 5A-D). PLX4032 significantly increased c-Met expression in A2058 cells compared to the ME group, while it significantly decreased c-Met expression in the A375R cells (Fig. 5A-D). To verify that IS induced downregulation of MITF and c-Met by increasing ROS production, $\mathrm{H}_{2} \mathrm{O}_{2}$, exogenous ROS, was used to promote ROS generation and it was revealed that $\mathrm{H}_{2} \mathrm{O}_{2}$ could significantly downregulate MITF and c-Met expression in both A2058 and A375R cells (Fig. 5E). These results indicated that IS may improve the response to PLX4032 partially by increasing ROS production and subsequently inhibiting MITF and c-Met expression in resistant melanoma cells. 
A

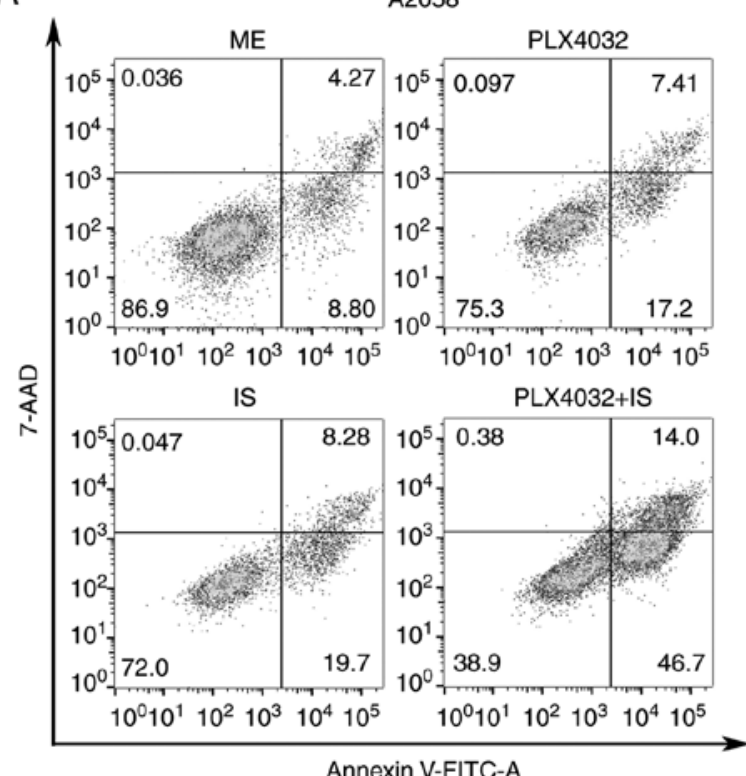

Annexin V-FITC-A
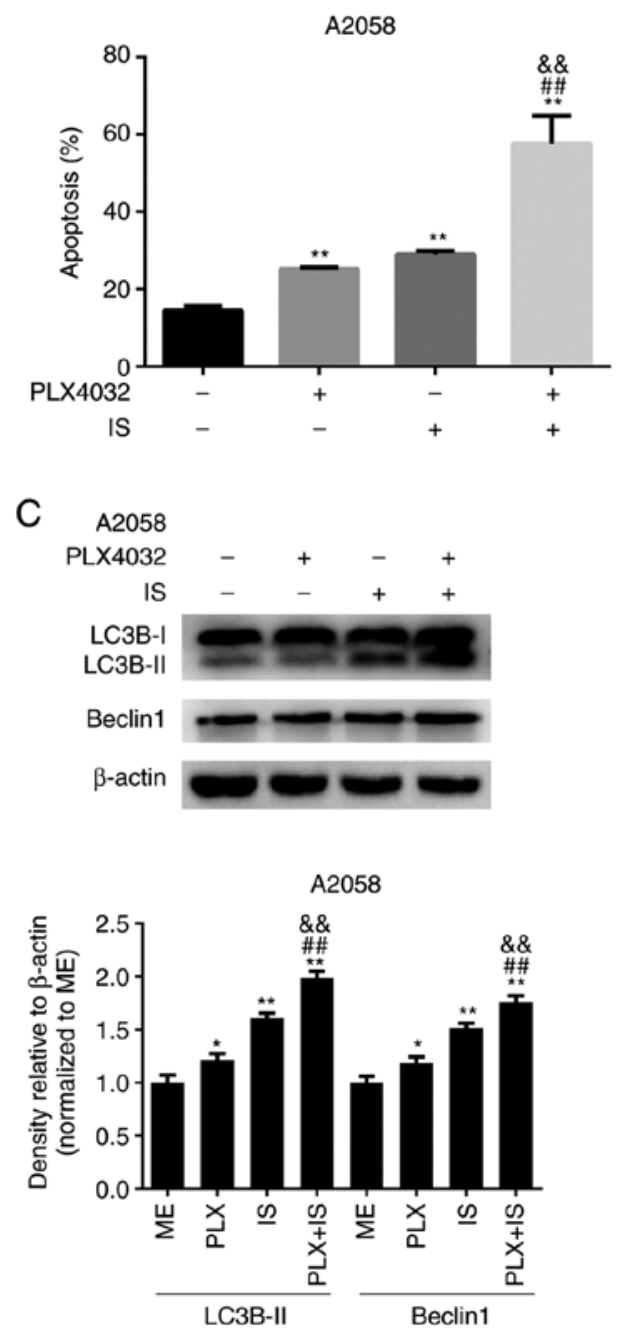

B

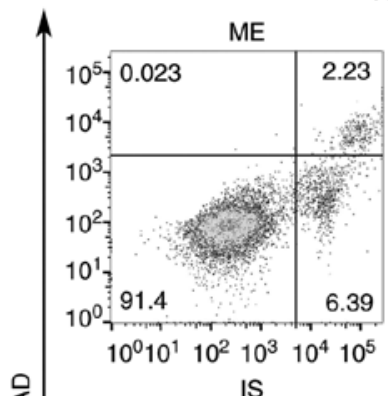

A375R
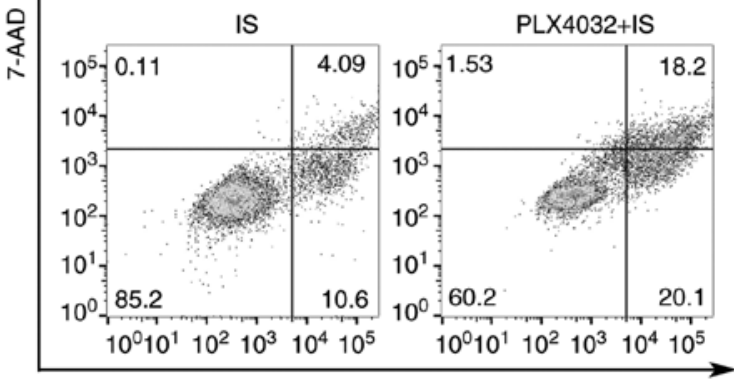

Annexin V-FITC-A

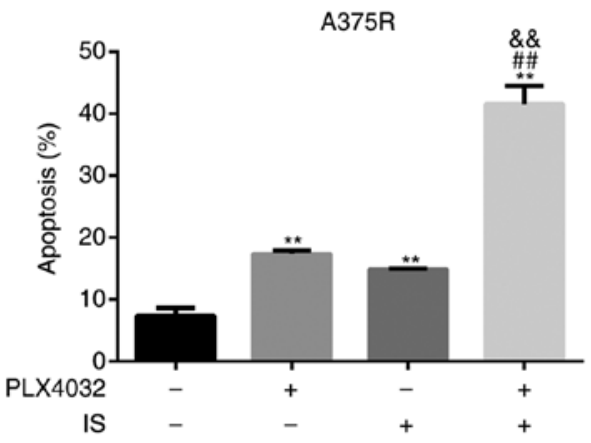

D
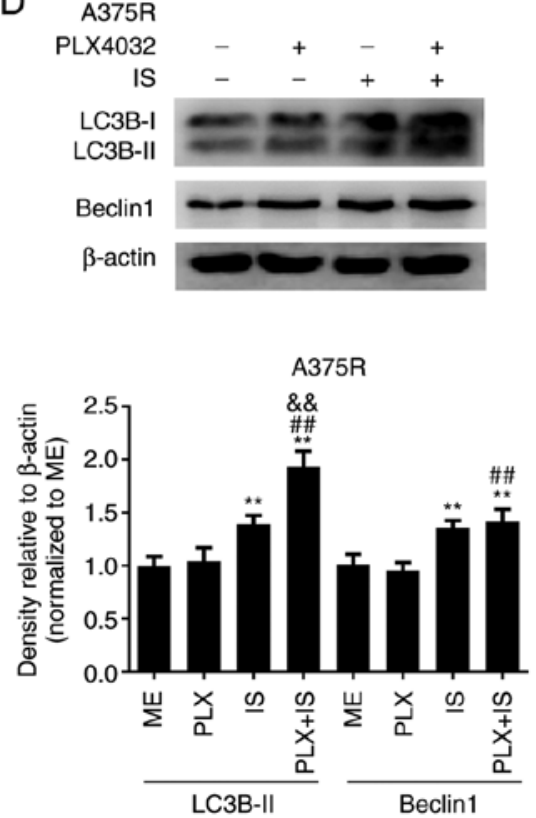

Figure 2. IS enhances PLX4032-induced apoptosis and autophagy in BRAF inhibitor-resistant melanoma cells. (A) A2058 or (B) A375R cells were treated with ME, PLX4032 $(10 \mu \mathrm{M})$, IS $(20 \mu \mathrm{M})$, and PLX4032 $(10 \mu \mathrm{M})+\mathrm{IS}(20 \mu \mathrm{M})$, respectively, for 24 or $72 \mathrm{~h}$, and cell apoptosis was detected by Annexin V and 7-AAD staining. The statistical analysis of the apoptosis rates of (A) A2058 and (B) A375R were performed by GraphPad Prism 6. (C) A2058 and (D) A375R cells were treated with ME, PLX4032 $(10 \mu \mathrm{M})$, IS $(20 \mu \mathrm{M})$, and PLX4032 $(10 \mu \mathrm{M})+\mathrm{IS}(20 \mu \mathrm{M})$, respectively, for $8 \mathrm{~h}$, and the protein levels of LC3B and Beclin1 were assessed by western blotting. Data were presented as the mean \pm standard error of the mean. For comparison of two independent groups, Student's t-test was used. For comparison of more than two independent groups, one-way ANOVA and subsequent Tukey's post hoc analysis were applied. ${ }^{*} \mathrm{P}<0.05$. ${ }^{* *}, \# \# \& \& \mathrm{P}<0.01$. The '*' refers to comparisons with the ME group. The '\#' refers to comparisons with the PLX4032 group. The '\&' refers to comparisons with the IS group. IS, icariside II; ME, medium control. 
A

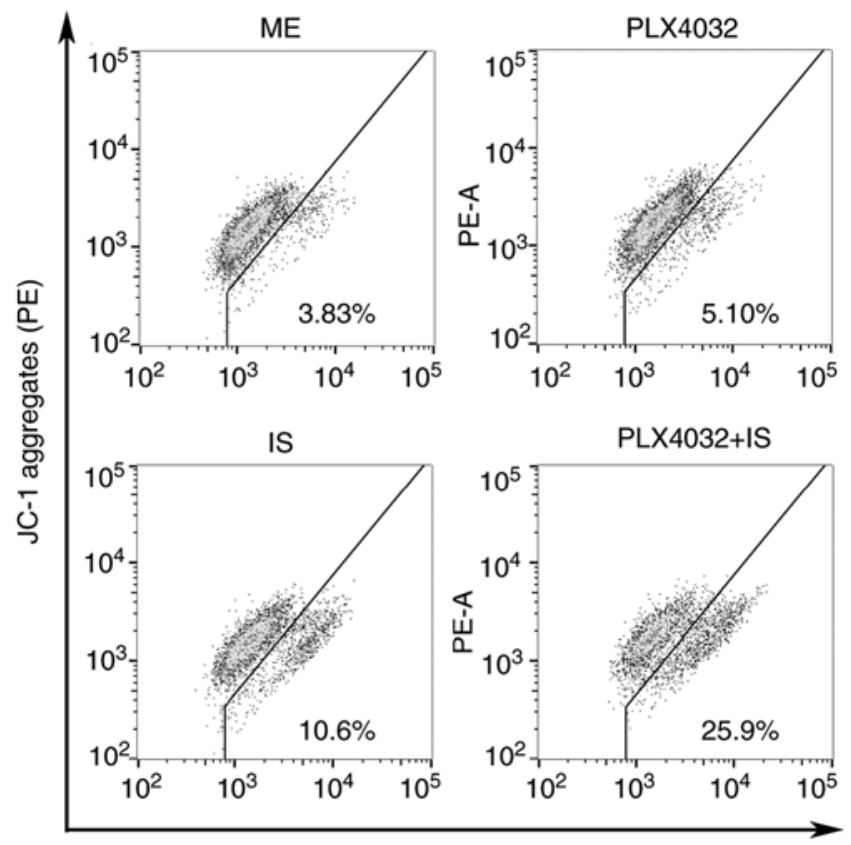

JC-1 monomers (FITC)

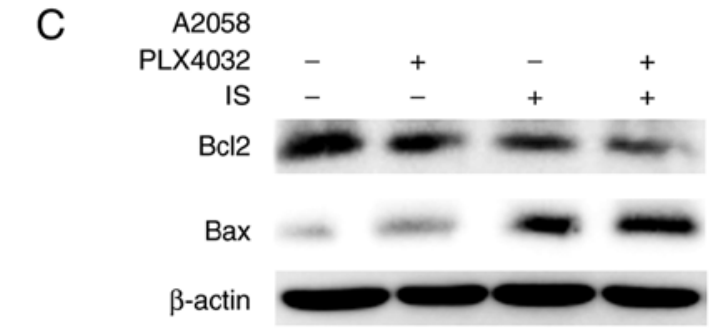

A2058

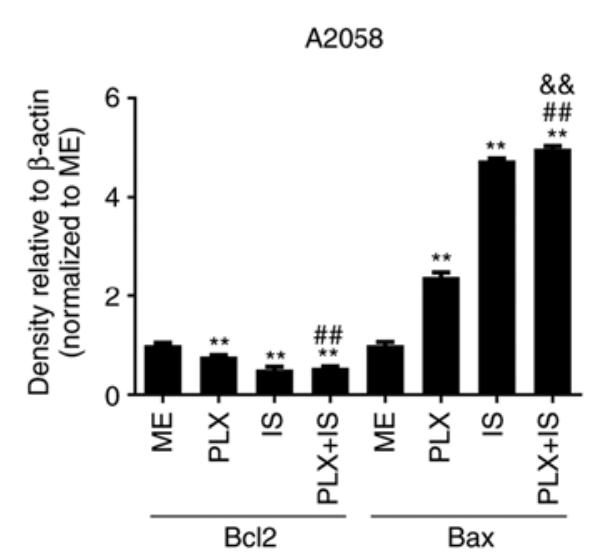

B

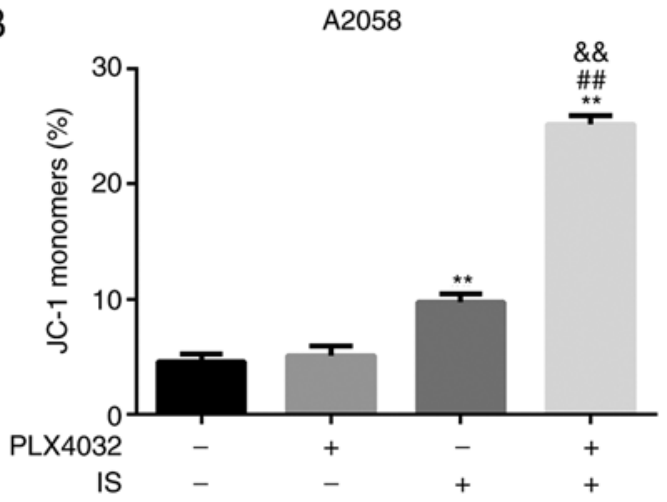

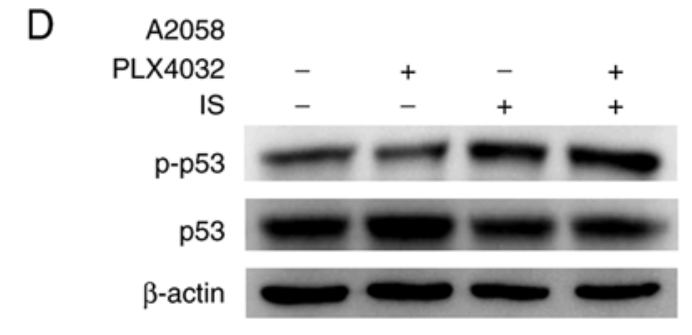

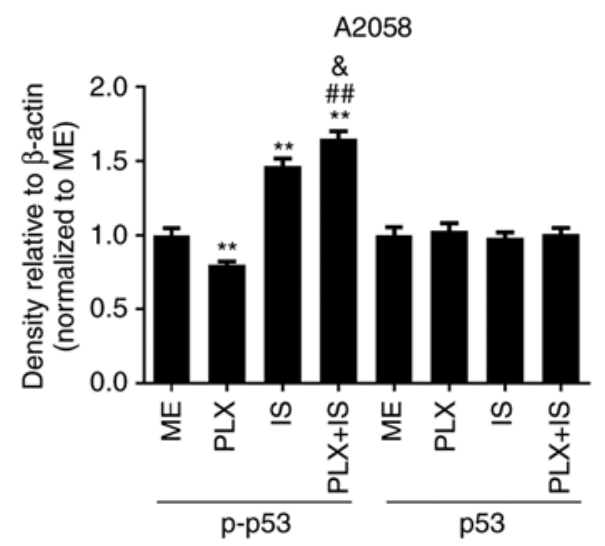

Figure 3. IS induces p53-dependent Bax accumulation and mitochondrial depolarization in BRAF inhibitor-resistant melanoma cells. (A) A2058 cells were treated with ME, PLX4032 $(10 \mu \mathrm{M})$, IS $(20 \mu \mathrm{M})$, and PLX4032 $(10 \mu \mathrm{M})+\mathrm{IS}(20 \mu \mathrm{M})$, respectively, for $18 \mathrm{~h}$, and then stained with the JC-1 fluorescent probe. The mitochondrial membrane potential was detected by flow cytometry. (B) The percentages of JC-1 monomers in A2058 cells were analyzed by GraphPad Prism 6. A2058 cells were treated with ME, PLX4032 (10 $\mu \mathrm{M})$, IS $(20 \mu \mathrm{M})$, and PLX4032 $(10 \mu \mathrm{M})+\mathrm{IS}(20 \mu \mathrm{M})$, respectively. (C) Twenty-four hours later, the protein levels of Bcl-2 and Bax were assessed by western blotting. (D) Eight hours later, the protein levels of p53 and phosphorylated p53 were assessed by western blotting. Data were presented as mean \pm standard error of the mean. For comparison of two independent groups, Student's t-test was used. For comparison of more than two independent groups, one-way ANOVA and subsequent Tukey's post hoc analysis were applied. ${ }^{* *, \# t, \& \&} \mathrm{P}<0.01$. The ‘*' refers to comparisons with the ME group. The '\#' refers to comparisons with the PLX4032 group. The ' $\&$ ' refers to comparisons with the IS group. IS, icariside II; p-p53, phosphorylated p53; ME, medium control.

\section{Discussion}

IS, a natural compound extracted from Herba Epimedii, exhibits multiple biological and pharmacological activities, including anti-inflammatory, anti-osteoporosis, anti-aging, and anticancer properties (12). As an anticancer agent, it is reported to inhibit cell proliferation and induce cell apoptosis in diverse cancer types $(12,26)$. Furthermore, it has been demonstrated 
A

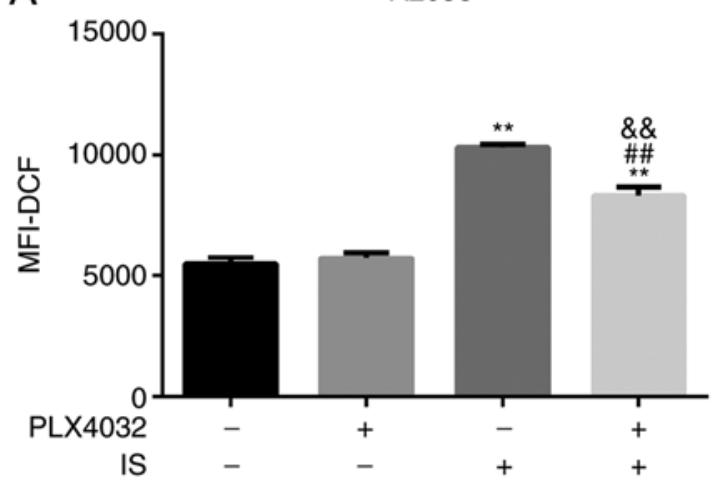

B

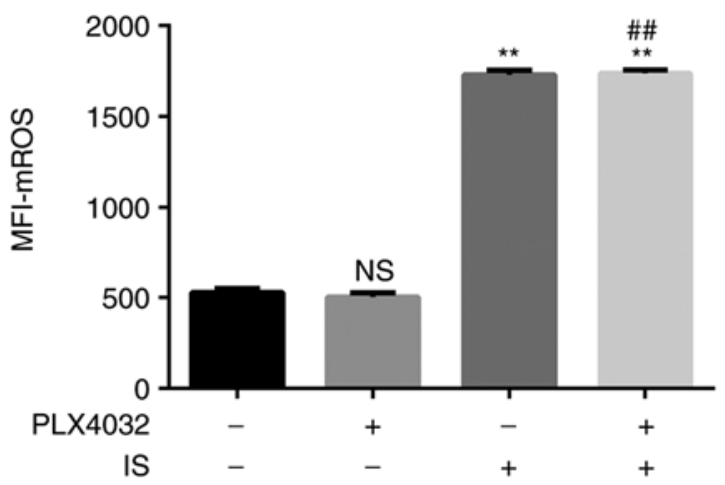

C

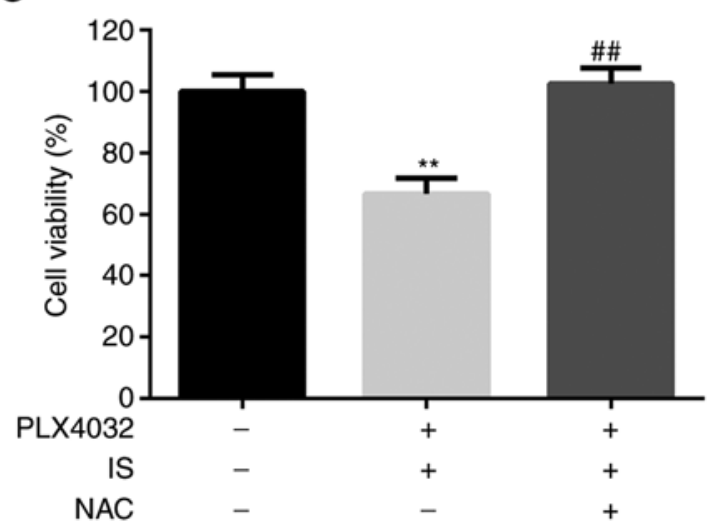

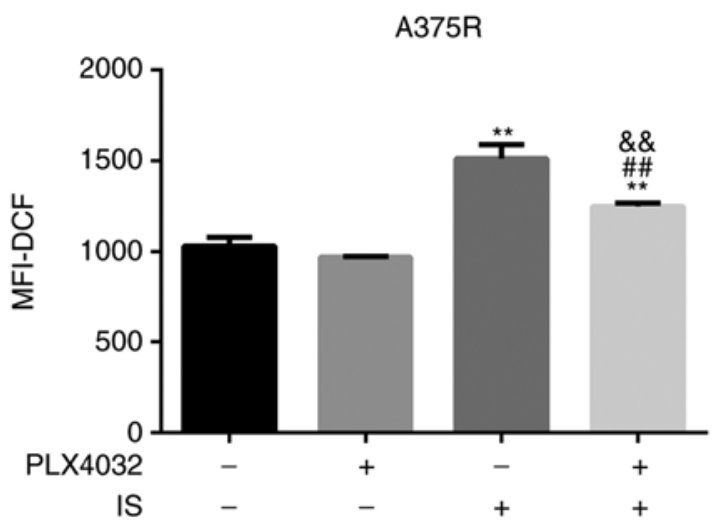

A375R

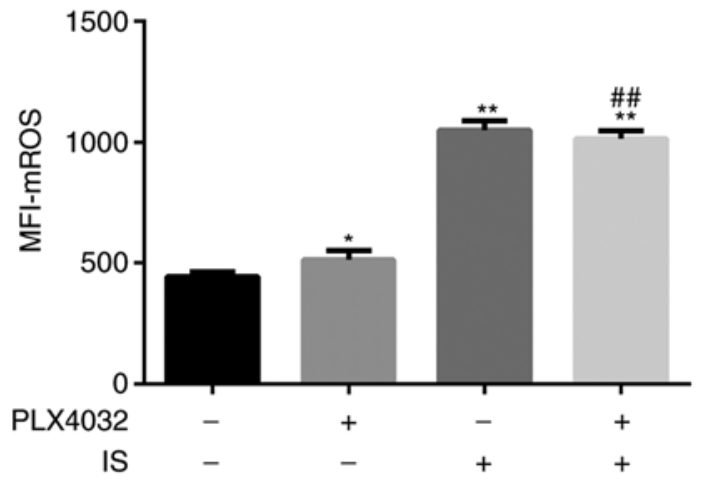

A2058

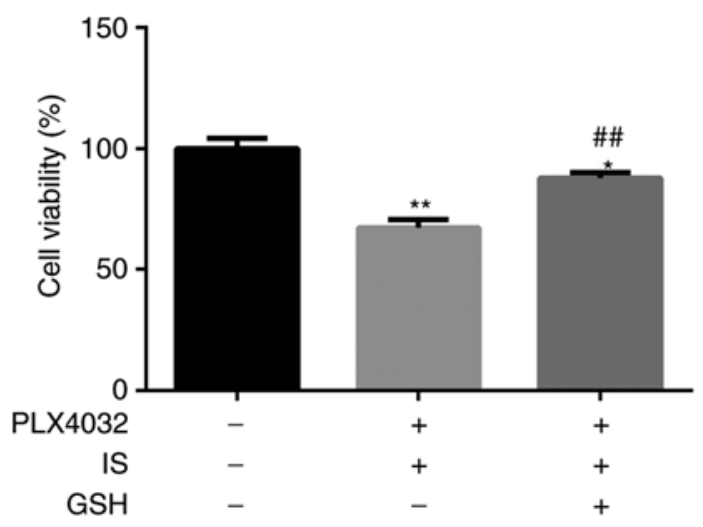

Figure 4. IS promotes mitochondria-dependent ROS production in BRAF inhibitor-resistant melanoma cells. (A) Both A2058 and A375R cells were treated with ME, PLX4032 $(10 \mu \mathrm{M})$, IS $(20 \mu \mathrm{M})$, and PLX4032 $(10 \mu \mathrm{M})+\mathrm{IS}(20 \mu \mathrm{M})$, respectively, for $24 \mathrm{~h}$. ROS levels were examined using a ROS assay kit. (B) Mitochondrial ROS levels were examined using a MitoROS ${ }^{\mathrm{TM}} 580$ kit. A2058 cells were pre-treated with (C) NAC (5 mM) or (D) GSH (1 mM) for $1 \mathrm{~h}$, and then treated with ME or PLX4032 $(10 \mu \mathrm{M})+\mathrm{IS}(20 \mu \mathrm{M})$ for $18 \mathrm{~h}$. The cell viabilities were assessed by MTT assay. Data were presented as the mean \pm standard error of the mean. For comparison of two independent groups, Student's t-test was used. For comparison of more than two independent groups,

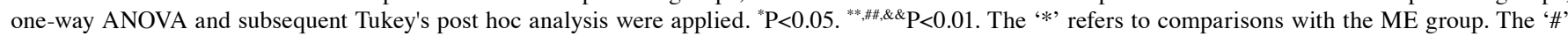
refers to comparisons with the PLX4032 group. The ' $\&$ ' refers to comparisons with the IS group. IS, icariside II; ROS, reactive oxygen species; NAC, N-acetyl cysteine; GSH, glutathione; ME, medium control.

to overcome resistance to traditional therapies, such as chemotherapies $(15,16)$. In the present study, it was revealed that IS improved the therapeutic benefits of PLX4032 in melanoma cells with intrinsic or acquired resistance to BRAF inhibitors.

Autophagy, a highly conserved catabolic process mediated by lysosomes, plays an important role in maintaining the internal environment homeostasis and cell survival $(27,28)$. It was also reported to promote cell death (28). In the present study, it was revealed that IS with or without PLX4032 significantly promoted the expression of autophagy-related proteins. It was surmised that IS induces ROS generation and p53 activation to promote both apoptosis and autophagy, thus inducing cell death.

ROS generation plays an important role in inducing mitochondrial apoptosis by regulating apoptotic proteins, such as Bcl-2 and Bax (29,30). ROS levels were reported 
A

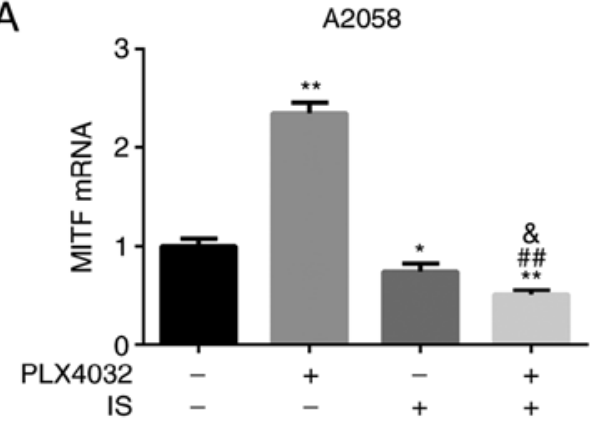

A2058

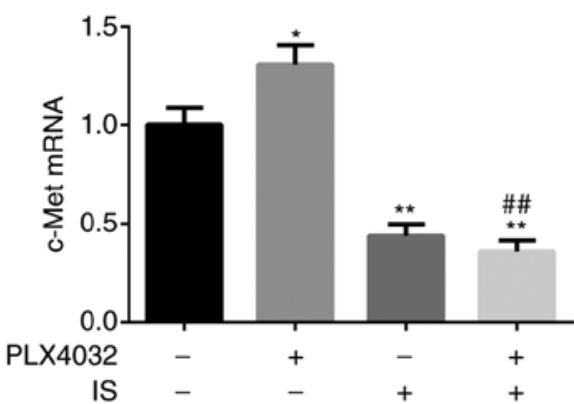

B

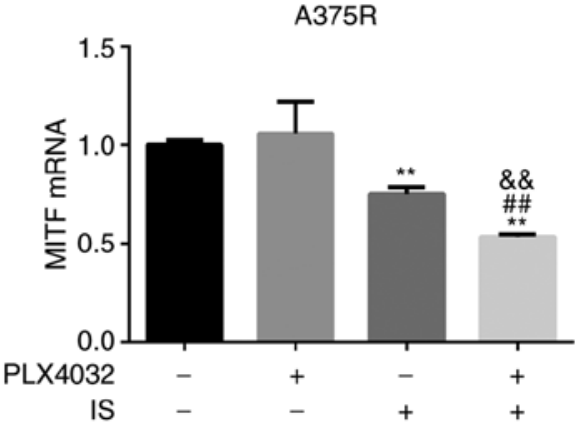

A375R

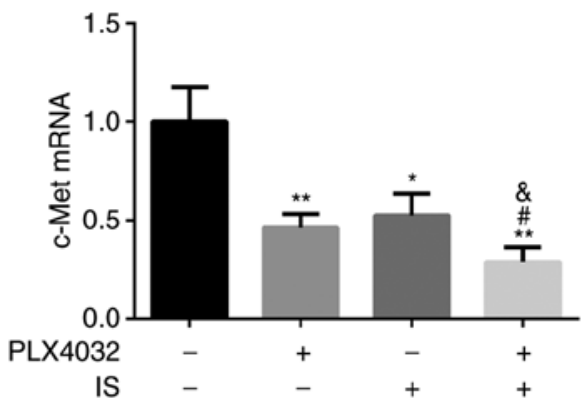

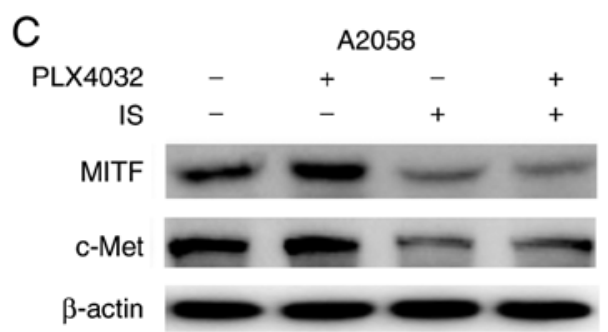

D
A2058

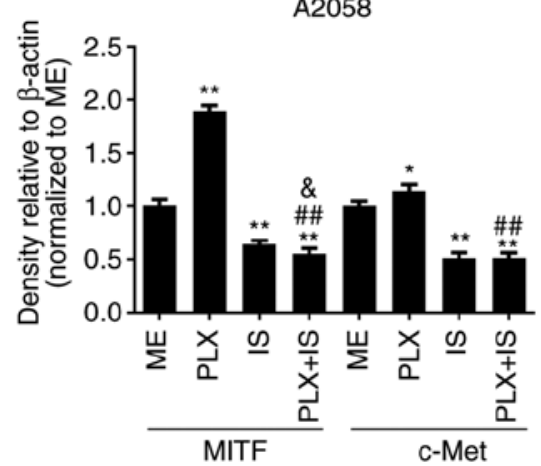

A375R

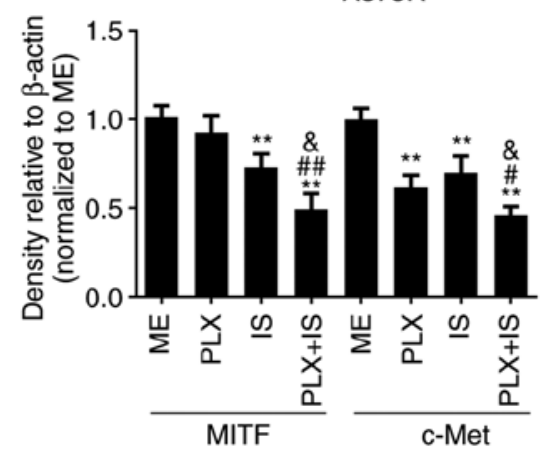

$E$

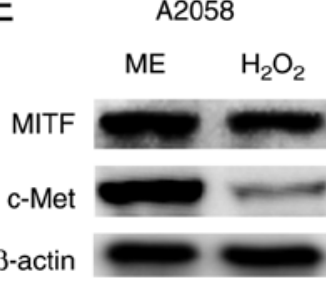

Figure 5. IS reduces the expression of MITF and c-Met by promoting ROS production. Both (A) A2058 and (B) A375R cells were treated with ME, PLX4032 $(10 \mu \mathrm{M})$, IS $(20 \mu \mathrm{M})$, and PLX4032 $(10 \mu \mathrm{M})+\mathrm{IS}(20 \mu \mathrm{M})$, respectively, for $8 \mathrm{~h}$, and the mRNA levels of MITF and c-Met were detected by qRT-PCR. Both (C) A2058 and (D) A375R cells were treated with ME, PLX4032 (10 $\mu \mathrm{M})$, IS $(20 \mu \mathrm{M})$, and PLX4032 $(10 \mu \mathrm{M})+\mathrm{IS}(20 \mu \mathrm{M})$, respectively, for $24 \mathrm{~h}$, and the protein levels of MITF and c-Met were detected by western blotting. (E) A2058 cells were treated with ME or $\mathrm{H}_{2} \mathrm{O}_{2}(250 \mu \mathrm{M})$ for $6 \mathrm{~h}$, and the protein levels of MITF and c-Met were examined by western blotting. Data were presented as the mean \pm standard error of the mean. For comparison of two independent groups, Student's t-test was used. For comparison of more than two independent groups, one-way ANOVA and subsequent Tukey's post hoc analysis were applied.

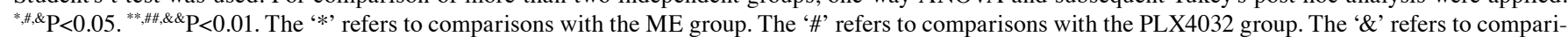
sons with the IS group. IS, icariside II; ME, medium control; MITF, microphthalmia-associated transcription factor; c-Met, tyrosine-protein kinase Met.

to be significantly upregulated in BRAF inhibitor-treated BRAF V600E melanoma cells and BRAF inhibitor-resistant melanoma cells irrespective of the presence of BRAF inhibitors (30). In the present study, it was revealed that PLX4032 alone exerted little effect on ROS generation and mitochondrial depolarization in melanoma cells with either intrinsic or acquired resistance to BRAF inhibitor resistance. The possible reason is that the ROS levels in resistant melanoma cells are already high, and these cells exhibited no response to BRAF inhibitors. In addition, higher ROS generation has been 
widely reported to sensitize resistant cells to BRAF inhibitors. Elesclomol, a pro-oxidative drug, was revealed to increase intracellular ROS production and melanoma cell death in a dose-dependent manner. Elesclomol was further indicated to significantly inhibit tumor growth in SCID mice xenografted with vemurafenib-resistant A375 cells and tumor fragments from melanoma patients by decreasing cell proliferation and inducing cell apoptosis (31). A100, a ROS-activated prodrug, was demonstrated to sensitize several dabrafenib-resistant melanoma cell lines to dabrafenib by inducing DNA damage and inhibiting cell proliferation (31). TRAM-34, a potassium channel inhibitor, was also revealed to improve the therapeutic benefits of vemurafenib by increasing intracellular ROS levels, decreasing mitochondrial membrane potential, and enhancing pro-apoptotic pathways in melanoma (32). In accordance with these findings, it was revealed that IS combined with PLX4032 could significantly increase ROS production, and subsequently lead to p53-dependent activation of apoptotic proteins and mitochondrial depolarization. In addition, ROS scavengers, NAC and GSH, reversed IS-induced enhancement of the response to PLX4032 in BRAF inhibitor-resistant melanoma cells.

Notably, it was revealed that both PLX4032 and IS could inhibit cell proliferation and induce apoptosis in PLX4032-resistant melanoma. However, IS could increase ROS generation and subsequently increase Bax and decrease Bcl-2, while PLX4032 had little effect on ROS generation and subsequent Bax and Bcl-2 expression. The mechanisms of IS and PLX4032 in melanoma treatment may be different. It is well-known that MEK-ERK signaling is one of the major targets of PLX4032. It was revealed that high concentration of PLX4032 could still inhibit MEK-ERK signaling in PLX4032-resistant melanoma cells, though this effect was not as significant as that in parental melanoma cells (data not shown).

MITF is an indispensable factor in pigmentation and in the development of the melanocytic lineage (33). High MITF levels inhibit proliferation by cell cycle arrest, and cells lacking MITF display invasive properties $(34,35)$. However, MITF has been revealed to play an oncogenic role in the tumorigenesis of melanoma, since it is amplified in $15 \%$ of metastatic melanomas (36). MITF was further reported to be upregulated by BRAF/MEK inhibitors in a MAPK-dependent manner at an early stage of patient treatment (37). In addition, high MITF levels were demonstrated to allow melanoma cells to avoid BRAF/MEK inhibitor-induced cell death even when the MAPK signaling pathway was completely blocked, thus contributing to MAPK inhibitor resistance in melanoma $(38,39)$. The present study revealed that PLX4032 could not decrease MITF expression in BRAF inhibitor-resistant melanoma cells, while IS with or without PLX4032 significantly decreased MITF expression. Therefore, it is highly possible that IS overcomes BRAF inhibitor resistance by downregulating MITF expression in melanoma.

In addition, MITF may be regulated by ROS generation. Ko and Cho demonstrated that Phytol suppressed melanogenesis by promoting ROS production, and subsequently activating ERK, followed by proteasomal degradation of MITF (40). Furthermore, MITF-negative melanoma cells were revealed to have lower survival rates than MITF-positive melanoma cells under ROS stress (41). In the present study, the regulatory role of ROS on MITF was confirmed, since it was revealed that exogenous ROS, $\mathrm{H}_{2} \mathrm{O}_{2}$, could significantly decrease MITF expression.

C-Met, an important member of the receptor tyrosine kinase (RTK) family, is the ligand of HGF. Activated c-Met was reported to enhance cell proliferation in BRAF inhibitor-resistant melanoma cells (42). The combination of BRAF inhibitor and c-Met inhibitor revealed significant therapeutic benefit in BRAF-mutant melanoma cells (43). In addition, c-Met is directly transcriptionally regulated by MITF in melanocytes and melanoma cells (25). In the present study, it was revealed that IS with or without PLX4032 could decrease c-Met expression in BRAF inhibitor-resistant melanoma cells However, IS could inhibit c-Met expression to a larger degree in A2058 cells when compared to A375R cells. A2058 cells have intrinsic resistance to PLX4032, while A375R cells have acquired resistance to PLX4032. This may be, because they are different cell lines. In addition, $\mathrm{H}_{2} \mathrm{O}_{2}$ could significantly decrease c-Met. Therefore, it is highly possible that IS improves the response to BRAF inhibitors by downregulating MITF and c-Met expression in a ROS-dependent manner.

Notably, IS may sensitize BRAF inhibitor resistance by other mechanisms besides inducing ROS generation and regulating MITF expression. Our previous studies demonstrated that IS could inhibit EGFR signaling (14) and STAT3 signaling (16) in cancer cells. Since EGFR and STAT3 were involved in BRAF inhibitor resistance in melanoma, it was hypothesized that IS may reverse BRAF inhibitor resistance through EGFR and STAT3 signaling. Further studies are necessary to verify this hypothesis.

In conclusion, the present study demonstrated that IS overcomes BRAF inhibitor resistance by improving ROS generation and subsequently inducing ROS-dependent apoptosis and autophagy and downregulating MITF expression in BRAF inhibitor-resistant melanoma cells.

\section{Acknowledgements}

We would like to thank Dr Jianhua Huang from the Department of Integrative Medicine, Huashan Hospital, Fudan University, Shanghai, China, for his valuable suggestions on the design of the project.

\section{Funding}

The present study was supported by grants from the National Natural Science Foundation of China (nos. 81673917 and 81973582) and the Shanghai Science and Technology Committee (13JC1401401).

\section{Availability of data and materials}

The datasets used and/or analysed during the current study are available from the corresponding author on reasonable request.

\section{Authors' contributions}

JX and JW designed the research and interpreted the data. XL and ZL performed the experiments and wrote the manuscript. 
ML, JC and SH analyzed the data. All authors read and approved the manuscript and agree to be accountable for all aspects of the research in ensuring that the accuracy or integrity of any part of the work are appropriately investigated and resolved.

\section{Ethics approval and consent to participate}

Not applicable.

\section{Patient consent for publication}

Not applicable.

\section{Competing interests}

All authors declare that they have no competing interests.

\section{References}

1. Siegel RL, Miller KD and Jemal A: Cancer statistics, 2018. CA Cancer J Clin 68: 7-30, 2018.

2. Wilson MA and Schuchter LM: Chemotherapy for Melanoma. Cancer Treat Res 167: 209-229, 2016.

3. Alexandrov LB, Nik-Zainal S, Wedge DC, Aparicio SA, Behjati S, Biankin AV, Bignell GR, Bolli N, Borg A, Borresen-Dale AL, et al: Signatures of mutational processes in human cancer. Nature 500: 415-421, 2013.

4. Colombino M, Capone M, Lissia A, Cossu A, Rubino C, De Giorgi V, Massi D, Fonsatti E, Staibano S, Nappi O, et al: $\mathrm{BRAF} / \mathrm{NRAS}$ mutation frequencies among primary tumors and metastases in patients with melanoma. J Clin Oncol 30 $2522-2529,2012$

5. Luebker SA and Koepsell SA: Diverse mechanisms of BRAF inhibitor resistance in melanoma identified in clinical and preclinical studies. Front Oncol 9: 268, 2019.

6. Sosman JA, Kim KB, Schuchter L, Gonzalez R, Pavlick AC, Weber JS, McArthur GA, Hutson TE, Moschos SJ Flaherty KT, et al: Survival in BRAF V600-mutant advanced melanoma treated with vemurafenib. N Engl J Med 366: 707-714, 2012.

7. Chapman PB, Hauschild A, Robert C, Haanen JB, Ascierto P, Larkin J, Dummer R, Garbe C, Testori A, Maio M, et al: Improved survival with vemurafenib in melanoma with BRAF V600E mutation. N Engl J Med 364: 2507-2516, 2011.

8. Long GV, Stroyakovskiy D, Gogas H, Levchenko E, de Braud F, Larkin J, Garbe C, Jouary T, Hauschild A, Grob JJ, et al: Combined BRAF and MEK inhibition versus BRAF inhibition alone in melanoma. N Engl J Med 371: 1877-1888, 2014.

9. Flaherty KT, Infante JR, Daud A, Gonzalez R, Kefford RF, Sosman J, Hamid O, Schuchter L, Cebon J, Ibrahim N, et al: Combined BRAF and MEK inhibition in melanoma with BRAF V600 mutations. N Engl J Med 367: 1694-1703, 2012.

10. Hauschild A, Grob JJ, Demidov LV, Jouary T, Gutzmer R, Millward M, Rutkowski P, Blank CU, Miller WJ Jr, Kaempgen E, et al: Dabrafenib in BRAF-mutated metastatic melanoma: A multicentre, open-label, phase 3 randomised controlled trial. Lancet 380: 358-365, 2012.

11. Robert C, Karaszewska B, Schachter J, Rutkowski P, Mackiewicz A, Stroiakovski D, Lichinitser M, Dummer R, Grange F, Mortier L, et al: Improved overall survival in melanoma with combined dabrafenib and trametinib. N Engl J Med 372: 30-39, 2015.

12. Khan M, Maryam A, Qazi JI and Ma T: Targeting apoptosis and multiple signaling pathways with Icariside II in cancer cells. Int J Biol Sci 11: 1100-1112, 2015

13. Song J, Shu L, Zhang Z, Tan X, Sun E, Jin X, Chen Y and Jia X: Reactive oxygen species-mediated mitochondrial pathway is involved in Baohuoside I-induced apoptosis in human non-small cell lung cancer. Chem Biol Interact 199: 9-17, 2012.

14. Wu J, Zuo F, Du J, Wong PF, Qin H and Xu J: Icariside II induces apoptosis via inhibition of the EGFR pathways in A431 human epidermoid carcinoma cells. Mol Med Rep 8: 597-602, 2013.
15. Wu J, Guan M, Wong PF, Yu H, Dong J and Xu J: Icariside II potentiates paclitaxel-induced apoptosis in human melanoma A375 cells by inhibiting TLR4 signaling pathway. Food Chem Toxicol 50: 3019-3024, 2012.

16. Du J, Wu J, Fu X, Tse AK, Li T, Su T and Yu ZL: Icariside II overcomes TRAIL resistance of melanoma cells through ROS-mediated downregulation of STAT3/cFLIP signaling. Oncotarget 7: 52218-52229, 2016.

17. Nazarian R, Shi H, Wang Q, Kong X, Koya RC, Lee H, Chen Z, Lee MK, Attar N, Sazegar H, et al: Melanomas acquire resistance to B-RAF(V600E) inhibition by RTK or N-RAS upregulation. Nature 468: 973-977, 2010.

18. Chen G, Yang Y, Xu C and Gao S: A Flow Cytometry-based Assay for measuring mitochondrial membrane potential in cardiac myocytes after hypoxia/reoxygenation. J Vis Exp, 2018.

19. Feng JH, Nakagawa-Goto K, Lee KH and Shyur LF: A Novel plant sesquiterpene lactone derivative, DETD-35, suppresses BRAFV600E mutant melanoma growth and overcomes acquired vemurafenib resistance in mice. Mol Cancer Ther 15: 1163-1176, 2016.

20. Westphal D, Kluck RM and Dewson G: Building blocks of the apoptotic pore: How Bax and Bak are activated and oligomerize during apoptosis. Cell Death Differ 21: 196-205, 2014.

21. Vaseva AV and Moll UM: The mitochondrial p53 pathway. Biochim Biophys Acta 1787: 414-420, 2009.

22. Vergani E, Vallacchi V, Frigerio S, Deho P, Mondellini P, Perego P, Cassinelli G, Lanzi C, Testi MA, Rivoltini L, et al: Identification of MET and SRC activation in melanoma cell lines showing primary resistance to PLX4032. Neoplasia 13: 1132-1142, 2011.

23. Aida S, Sonobe Y, Tanimura H, Oikawa N, Yuhki M, Sakamoto H and Mizuno T: MITF suppression improves the sensitivity of melanoma cells to a BRAF inhibitor. Cancer Lett 409: 116-124, 2017.

24. Filitis DC, Rauh J and Mahalingam M: The HGF-cMET signaling pathway in conferring stromal-induced BRAF-inhibitor resistance in melanoma. Melanoma Res 25: 470-478, 2015.

25. McGill GG, Haq R, Nishimura EK and Fisher DE: c-Met expression is regulated by Mitf in the melanocyte lineage. J Biol Chem 281: 10365-10373, 2006.

26. Chen M, Wu J, Luo Q, Mo S, Lyu Y, Wei Y and Dong J: The anticancer properties of herba epimedii and its main bioactive componentsicariin and icariside II. Nutrients 8: pii: E563, 2016.

27. Mizushima N and Klionsky DJ: Protein turnover via autophagy: Implications for metabolism. Annu Rev Nutr 27: 19-40, 2007.

28. Das G, Shravage BV and Baehrecke EH: Regulation and function of autophagy during cell survival and cell death. Cold Spring Harb Perspect Biol 4: pii: a008813, 2012.

29. Franke JC, Plotz M, Prokop A, Geilen CC, Schmalz HG and Eberle J: New caspase-independent but ROS-dependent apoptosis pathways are targeted in melanoma cells by an iron-containing cytosine analogue. Biochem Pharmacol 79: 575-586, 2010.

30. Quast SA, Berger A and Eberle J: ROS-dependent phosphorylation of Bax by wortmannin sensitizes melanoma cells for TRAIL-induced apoptosis. Cell Death Dis 4: e839, 2013.

31. Corazao-Rozas P, Guerreschi P, Jendoubi M, Andre F, Jonneaux A, Scalbert C, Garcon G, Malet-Martino M, Balayssac S, Rocchi S, et al: Mitochondrial oxidative stress is the Achille's heel of melanoma cells resistant to Braf-mutant inhibitor. Oncotarget 4: 1986-1998, 2013.

32. Bauer D, Werth F, Nguyen HA, Kiecker F and Eberle J: Critical role of reactive oxygen species (ROS) for synergistic enhancement of apoptosis by vemurafenib and the potassium channel inhibitor TRAM-34 in melanoma cells. Cell Death Dis 8: e2594, 2017.

33. Hodgkinson CA, Moore KJ, Nakayama A, Steingrimsson E, Copeland NG, Jenkins NA and Arnheiter H: Mutations at the mouse microphthalmia locus are associated with defects in a gene encoding a novel basic-helix-loop-helix-zipper protein. Cell 74: 395-404, 1993.

34. Carreira S, Goodall J, Aksan I, La Rocca SA, Galibert MD Denat L, Larue L and Goding CR: Mitf cooperates with Rb1 and activates p21Cip1 expression to regulate cell cycle progression. Nature 433: 764-769, 2005.

35. Carreira S, Goodall J, Denat L, Rodriguez M, Nuciforo P, Hoek KS, Testori A, Larue L and Goding CR: Mitf regulation of Dial controls melanoma proliferation and invasiveness. Genes Dev 20: 3426-3439, 2006. 
36. Garraway LA, Widlund HR, Rubin MA, Getz G, Berger AJ, Ramaswamy S, Beroukhim R, Milner DA, Granter SR, $\mathrm{Du} \mathrm{J}$, et al: Integrative genomic analyses identify MITF as a lineage survival oncogene amplified in malignant melanoma. Nature 436: 117-122, 2005.

37. Smith MP, Brunton H, Rowling EJ, Ferguson J, Arozarena I, Miskolczi Z, Lee JL, Girotti MR, Marais R, Levesque MP, et al: Inhibiting Drivers of Non-mutational drug tolerance is a salvage strategy for targeted melanoma therapy. Cancer Cell 29: 270-284, 2016.

38. Muller J, Krijgsman O, Tsoi J, Robert L, Hugo W, Song C, Kong X, Possik PA, Cornelissen-Steijger PD, Geukes Foppen MH, et al: Low MITF/AXL ratio predicts early resistance to multiple targeted drugs in melanoma. Nat Commun 5: 5712, 2014.

39. Smith MP, Ferguson J, Arozarena I, Hayward R, Marais R, Chapman A, Hurlstone A and Wellbrock C: Effect of SMURF2 targeting on susceptibility to MEK inhibitors in melanoma. J Natl Cancer Inst 105: 33-46, 2013.
40. Ko GA and Cho SK: Phytol suppresses melanogenesis through proteasomal degradation of MITF via the ROS-ERK signaling pathway. Chem Biol Interact 286: 132-140, 2018

41. Liu F, Fu Y and Meyskens FJ Jr: MiTF regulates cellular response to reactive oxygen species through transcriptional regulation of APE-1/Ref-1. J Invest Dermatol 129: 422-431, 2009.

42. Straussman R, Morikawa T, Shee K, Barzily-Rokni M, Qian ZR, Du J, Davis A, Mongare MM, Gould J, Frederick DT, et al: Tumour micro-environment elicits innate resistance to RAF inhibitors through HGF secretion. Nature 487: 500-504, 2012.

43. Etnyre D, Stone AL, Fong JT, Jacobs RJ, Uppada SB, Botting GM, Rajanna S, Moravec DN, Shambannagari MR, Crees Z, et al: Targeting c-Met in melanoma: Mechanism of resistance and efficacy of novel combinatorial inhibitor therapy. Cancer Biol Ther 15: 1129-1141, 2014 